J. Lake Sci.(湖泊科学), 2017, 29(4): 859-869

DOI 10. 18307/2017. 0409

(c) 2017 by Journal of Lake Sciences

\title{
太湖西北湖区浮游植物和无机、有机氮的时空分布特征"
}

\author{
叶琳琳 $^{1}$, 吴晓东 ${ }^{2}$,刘 波 ${ }^{1}$, 间德智 ${ }^{1}$,赵 力 $^{1}$ \\ (1: 南通大学地理科学学院, 南通 226000) \\ (2:中国科学院西北生态环境资源研究院,冰冻圈科学国家重点实验室,青藏高原冰冻圈观测研究站,兰州 730000)
}

\begin{abstract}
摘 要: 以太湖重度蓝藻水华发生的西北湖区为研究对象, 从河口至湖心区设置 5 个采样点, 于 2012 年 10 月至 2013 年 10 月逐月采集表层水体样品, 测定了水温、溶解氧和浮游细菌丰度, 并分析了浮游植物群落结构的组成、溶解性无机氮 (DIN) 和有机氮 (DON) 浓度以及氮磷比. 研究结果表明, 太湖西北湖区浮游植物主要由蓝藻、硅藻、绿藻和隐藻组成. 可能 由于风、浪等混合作用使太湖西北湖区不同采样点之间蓝藻细胞密度没有显著差异. 蓝藻生物量在浮游植物中所占比例 最高为 $34 \% \pm 15 \%$, 春季部分点位隐藻生物量高于 $50 \%$, 表明隐藻与蓝藻的相互竞争趋势显著. CCA 排序图结果表明, DIN 、DON 浓度以及总氮: 总磷比 (TN :TP 比) 是影响西北湖区浮游植物优势属分布的重要环境因子. 5 个采样点铵态氮 $\left(\mathrm{NH}_{4}^{+}-\mathrm{N}\right)$ 与 DIN 浓度具有显著差异, 与 DON 浓度没有显著差异. 夏季蓝藻水华暴发期间, 可能由于蓝藻的吸收利用引起 $\mathrm{NH}_{4}^{+}-\mathrm{N}$ 和硝态氮 $\left(\mathrm{NO}_{3}^{-}-\mathrm{N}\right)$ 浓度迅速降低. 此外, 由于 $\mathrm{NH}_{4}^{+}-\mathrm{N}$ 浓度还可能受到沉积物 $\mathrm{NH}_{4}^{+}-\mathrm{N}$ 释放的影响, 因此, 蓝藻细胞 密度与 $\mathrm{NO}_{3}^{-}-\mathrm{N}$ 的相关系数和显著水平均高于 $\mathrm{NH}_{4}^{+}-\mathrm{N}$. 夏季 $\mathrm{TN}: \mathrm{TP}$ 比和 DIN :TP 比降至最低, 表明该湖区浮游植物, 尤其 是蓝藻的生长可能受到氮限制. 蓝藻细胞密度与 DON 浓度呈显著负相关, 表明在氮限制条件下, DON 可能是蓝藻氮素利 用的重要补充.
\end{abstract}

关键词: 太湖; 浮游植物; 溶解性无机氮; 溶解性有机氮;氮限制

\section{Temporal and spatial distributions of phytoplankton and inorganic and organic nitrogen in northwest region of Lake Taihu}

\author{
YE Linlin ${ }^{1}$, WU Xiaodong ${ }^{2}, \mathrm{LIU}_{\mathrm{Bo}}{ }^{1}, \mathrm{YAN}_{\mathrm{Dezhi}}{ }^{1} \& \mathrm{ZHAO} \mathrm{\textrm {Li } ^ { 1 }}$ \\ (1: School of Geography Science, Nantong University, Nantong 226000, P.R.China) \\ (2: Cryosphere Research Station on the Qinghai-Tibetan Plateau, State Key Laboratory of Cryosphere Sciences, Northwest In- \\ stitute of Eco-Environment and Resources, Chinese Academy of Sciences, Lanzhou 730000, P.R.China)
}

\begin{abstract}
Surface water samples of five sampling sites from the estuary to lake center were collected from October 2012 to October 2013 in the northwest region of Lake Taihu, where with severe cyanobacterial bloom. Water temperature, dissolved oxygen, and bacterial abundance were analyzed, as well as the phytoplankton community, dissolved inorganic nitrogen (DIN) and dissolved organic nitrogen (DON) and nitrogen to phosphorus ratios. The phytoplankton assemblage was mainly composed of Cyanophyta, Bacillariophyta, Chlorophyta and Cryptophyta. No significant difference in Cyanophyta cell density was observed, which may be explained by the combined effects of current flow and wind. Cyanophyta biomass contributed to the phytoplankton with the maximum value of $34 \% \pm 15 \%$, but Cryptophyta biomass was more than $50 \%$ in some sampling sites in spring, suggesting a competition between Cryptophyta and Cyanophyta. The CCA analysis suggested that the distribution of dominant genera was affected by dissolved inorganic and organic nitrogen concentrations, and total nitrogen to total phosphorus ratio. Significant differences in ammonium nitrogen $\left(\mathrm{NH}_{4}^{+}-\mathrm{N}\right)$ and DIN concentrations were observed among the sampling sites, no significant difference in DON was observed.Utilization by Cyanophyta probably caused the decline of concentrations of $\mathrm{NH}_{4}^{+}-\mathrm{N}$ and nitrate nitrogen $\left(\mathrm{NO}_{3}^{-}-\mathrm{N}\right)$ during summer. Moreover, the dynamics of $\mathrm{NH}_{4}^{+}-\mathrm{N}$ was also affected by the release of $\mathrm{NH}_{4}^{+}-\mathrm{N}$ from sediment, thus, Cyanophyta cell density correlated more significantly with $\mathrm{NO}_{3}^{-}-\mathrm{N}$ than $\mathrm{NH}_{4}^{+}-\mathrm{N}$. TN :TP and DIN :TP decreased to the lowest values during Cyanophyta bloom, sugges-
\end{abstract}

* 国家自然科学基金项目 (41201076, 91547119) 资助. 2016-07-16 收稿; 2016-10-05 收修改稿. 叶琳琳 (1981 ) ,女,博士, 副教授;E-mail:yelinlin8164@163.com. 
ting that phytoplankton, especially Cyanophyta may be limited by nitrogen. A significant negative correlation was observed between Cyanophyta cell density and DON, indicating that DON can also be utilized by Cyanophyta during nitrogen limitation.

Keywords: Lake Taihu; phytoplankton; dissolved inorganic nitrogen; dissolved organic nitrogen; nitrogen limitation

氮素是水生生态系统的重要生源要素, 其中溶解性无机氮 (DIN) 是浮游植物吸收利用氮的主要形式. 一般认为铵态氮是浮游植物优先吸收利用的无机氮, 有研究表明富营养化湖泊中蓝藻吸收利用的氮中 $8 \%$ $98 \%$ 来源于铵态氮 ${ }^{[1]}$. 路娜等 ${ }^{[2]}$ 在巢湖研究发现, 硝态氮是影响浮游植物分布的重要因素, 并且有研究表明 硝态氮能被硅藻优先吸收利用 ${ }^{[3]}$. 这些研究结果表明, 不同湖泊和浮游植物群落结构的不同导致藻类吸收 利用的主要无机氮形式存在差异. 近来大量研究结果表明 ${ }^{[4-5]}$, 浮游植物在生长过程中会受到氮素限制作用. 在日本富营养化湖泊 Inba 研究发现 ${ }^{[5]}$, 夏季水体 DIN 浓度迅速降低, 蓝藻生长受到氮限制. 而溶解性有机 氮 (DON) 是水生生态系统中总溶解性氮 ( TDN) 的重要组分 ${ }^{[6]}$, 在以色列 Kinneret 湖研究发现 ${ }^{[6]}$, 夏季 DON 在 TDN 中所占比例达到 $89 \%$. DON 具有一定生物可利用性 ${ }^{[7]}$, 可以被浮游植物直接或间接吸收利用. Dai 等 ${ }^{[8]}$ 通过室内培养实验研究发现, 从滇池分离得到的无菌微囊藻株能吸收利用 DON 中氨基酸组分维持自 身生长和毒素合成. 综上所述, DON 也是影响浮游植物生长的重要氮素形态, 并且在水体出现氮限制情况 下, 能为浮游植物的生长提供重要氮源补充.

太湖位于苏、浙两省交界处, 是中国的第三大淡水湖泊. 近年来, 太湖蓝藻水华频发, 但目前关于浮游植 物和氮素的时空分布及其相互关系的研究主要集中在 DIN 方面, 而对 DON 的研究较少. Xu 等 ${ }^{[4]}$ 在太湖梅 梁湾研究发现该湖区夏季水体出现氮限制, 但考虑到太湖作为大型浅水湖泊, 其营养盐和浮游植物分布存 在较大的空间差异性, 其他藻型湖区在蓝藻水华暴发期间是否也会出现氮限制? 并且在这种氮限制环境 下, DON 能否被蓝藻吸收利用? 因此, 本研究以太湖西北湖区为研究对象, 分析不同季节水质参数 (水温、溶 解氧和浮游细菌丰度) 以及浮游植物群落组成, 明确了无机和有机氮的时空分布特征, 并运用典范对应分析 (CCA) 探讨浮游植物群落与各氮素形态之间的关系, 为太湖富营养化防治和氮素循环研究提供重要参考 依据.

\section{1 材料与方法}

\section{1 样品采集与分析方法}

太湖蓝藻水华主要发生在西北湖区 ${ }^{[9]}$, 因此本文以西北湖区为研究对象, 从河口至湖心设置 5 个采样

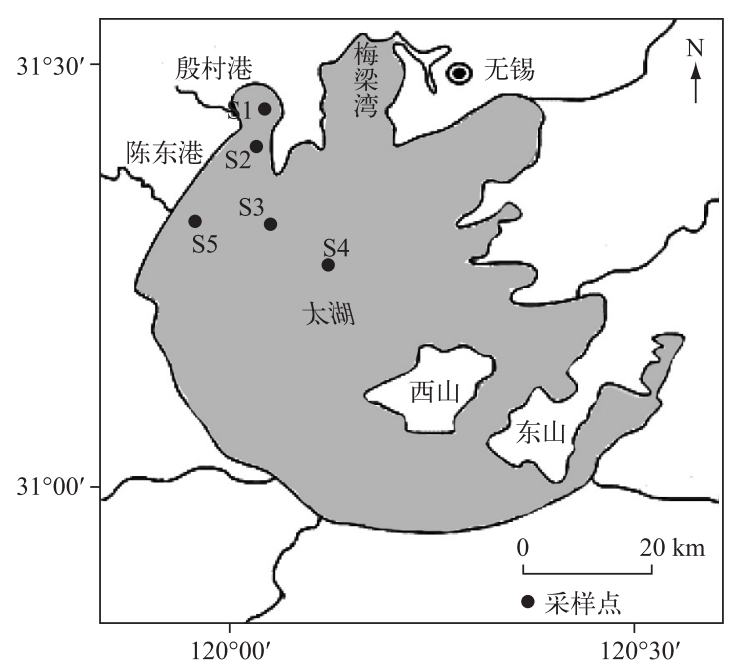

图 1 研究区域采样点设置

Fig.1 Location of the sampling sites in studied area 点, S1 和 S5 点位位于河口区, 靠近人湖河流尹 村港和陈东港. S4 点位位于湖心区. 用 GPS 定 位系统对研究区域采样点精确定位 (图 1), 于 2012 年 10 月至 2013 年 10 月, 每月采集表层水 体样品. 用 YSI 现场记录水温和溶解氧浓度的变 化. $1 \mathrm{~L}$ 水样加人 $10 \mathrm{ml}$ 鲁哥试剂固定, 在实验室 沉淀浓缩至 $30 \mathrm{ml}$, 在倒置显微镜下进行鉴定和 计数, 浮游植物的鉴定方法参照《中国淡水藻 类: 系统、分类及生态》 ${ }^{[10]}$. 根据浮游植物个体形 状参数和细胞数计算藻细胞体积, 再乘以密度得 到生物量. 浮游细菌样品用 $37 \%$ 甲醛固定, DAPI (4', 6-二脒基-2-苯基吲哚) 染色, 用表面苂光显 微镜 (Zeiss Axiovent $135 \mathrm{M}$, Germany) 测定浮游 细菌丰度. 水样置于有冰袋的保温箱内在 $4 \mathrm{~h}$ 内 带回实验室做进一步处理.

采用钼酸铵分光光度法测定总磷 ( TP ) 浓 度, 采用紫外分光光度法测定总氮 ( TN) 和总溶 
解性氮 $(\mathrm{TDN})$ 浓度, 硝态氮 $\left(\mathrm{NO}_{3}^{-}-\mathrm{N}\right)$ 浓度采用酚二磺酸分光光度法测定, 铵态氮 $\left(\mathrm{NH}_{4}^{+}-\mathrm{N}\right)$ 浓度采用纳氏试 剂分光光度法测定, 亚硝态氮 $\left(\mathrm{NO}_{2}^{-}-\mathrm{N}\right)$ 浓度采用重氮偶氮法测定, 正磷酸盐 $\left(\mathrm{PO}_{4}^{3-}-\mathrm{P}\right)$ 浓度采用锄酸铵分光 光度法测定 ${ }^{[11]}$. 溶解性无机氮 DIN $=\mathrm{NH}_{4}^{+}-\mathrm{N}+\mathrm{NO}_{3}^{-}-\mathrm{N}+\mathrm{NO}_{2}^{-}-\mathrm{N}$. 溶解性有机氮 DON $=\mathrm{TDN}-\mathrm{DIN}$. 用 TN :TP 比和 DIN :TP 比表征水体的氮磷比.

\section{2 数据分析}

非参数检验对总体分布不做假定, 因此本文中数据采用 Kruskal-Wallis 非参数检验比较 5 个采样点环境 因子参数及浮游植物细胞密度的差异性. 显著性水平 $P=0.05$. 通过 SPSS 16.0 软件使用皮尔森 (Pearson) 相 关系数法对浮游植物与环境因子进行相关分析. 利用 Canoco 软件对环境因子与浮游植物数据进行典范对应 分析. 优势度大于 0.02 为优势属 ${ }^{[12]}$, 人选物种数据矩阵. 首先对物种数据进行去趋势对应分析 (DCA), DCA 分析结果中的第一轴长度大于 3 时使用 CCA 分析, 否则使用基于线性的兄余分析 (RDA). 物种数据进行 $\lg (x+1)$ 转化. 环境数据矩阵排除了环境因子之间的自相关.

\section{2 结果与分析}

\section{1 太湖西北湖区水温、溶解氧浓度和浮游细菌丰度的 时空变化}

研究期间,太湖西北湖区 5 个采样点水温没有显著 差异 $(P>0.05, n=65)$. 水温变化范围为 $3.7 \sim 30.9^{\circ} \mathrm{C}$, 最 低和最高温度分别出现在 2013 年 1 和 7 月. 5 个采样点 之间溶解氧浓度具有显著差异 $(P<0.05, n=65)$, 且 5 个采样点溶解氧浓度都在夏季降至最低值. 浮游细菌丰 度没有显著差异 $(P>0.05, n=65)$, 浮游细菌丰度冬季 和早春 (2013 年 $1-3$ 月) 开始增加, 春、夏季产生波动. 除 S5 点位, 其他 4 个采样点浮游细菌丰度都在夏季 (2013 年 7-9 月) 达到最大值 (图 2).

\section{2 溶解性无机氮、溶解性有机氮和正磷酸盐浓度的时 空变化}

太湖西北湖区 5 个采样点 $\mathrm{NH}_{4}^{+}-\mathrm{N}$ 浓度有显著差异 $(P<0.001, n=65), \mathrm{S} 1$ 点位 $\mathrm{NH}_{4}^{+}-\mathrm{N}$ 浓度最高, $\mathrm{S} 4$ 点位 $\mathrm{NH}_{4}^{+}-\mathrm{N}$ 浓度最低. 5 个采样点 $\mathrm{NH}_{4}^{+}-\mathrm{N}$ 浓度都在冬季 (2013 年 $1-3$ 月) 达到最大值. $\mathrm{NO}_{3}^{-}-\mathrm{N}$ 浓度没有显著差 异 $(P>0.05, n=65) .5$ 个采样点 $\mathrm{NO}_{3}^{-}-\mathrm{N}$ 浓度都在春、夏 季( 2013 年 $4-8$ 月) 迅速降低. 5 个采样点 DIN 浓度具 有显著差异 $(P<0.001, n=65)$, 其中 S1 点位 DIN 浓度 最高, S4 点位 DIN 浓度最低. S3 和 S4 点位 DIN 浓度都 在春、夏季 ( 2013 年 $4-8$ 月) 迅速降低. 5 个采样点 DON 浓度先增加后逐渐降低, 没有显著差异 $(P>0.05$, $n=65$ ).

2012 年 12 月、 2013 年 3-7 月, $\mathrm{NO}_{3}^{-}-\mathrm{N}$ 浓度在 DIN 浓度中所占比例平均值大于 $50 \%$, 其中 2013 年 4 月， $\mathrm{NO}_{3}^{-}-\mathrm{N}$ 浓度在 DIN 浓度中所占比例达到 $74 \% \pm 6 \%$ 。 DON 浓度在 TDN 浓度中所占比例平均值小于 $50 \%$, 其 中夏季 DON 浓度在 TDN 浓度中所占比例最低 $(<30 \%) .5$ 个采样点 $\mathrm{NH}_{4}: \mathrm{NO}_{x}$ 比没有显著差异 $(P>$ $0.05, n=65)$, 夏季 $\mathrm{S} 1 、 \mathrm{~S} 3$ 和 $\mathrm{S} 4$ 点位 $\mathrm{NH}_{4}: \mathrm{NO}_{\mathrm{x}}$ 比迅速升
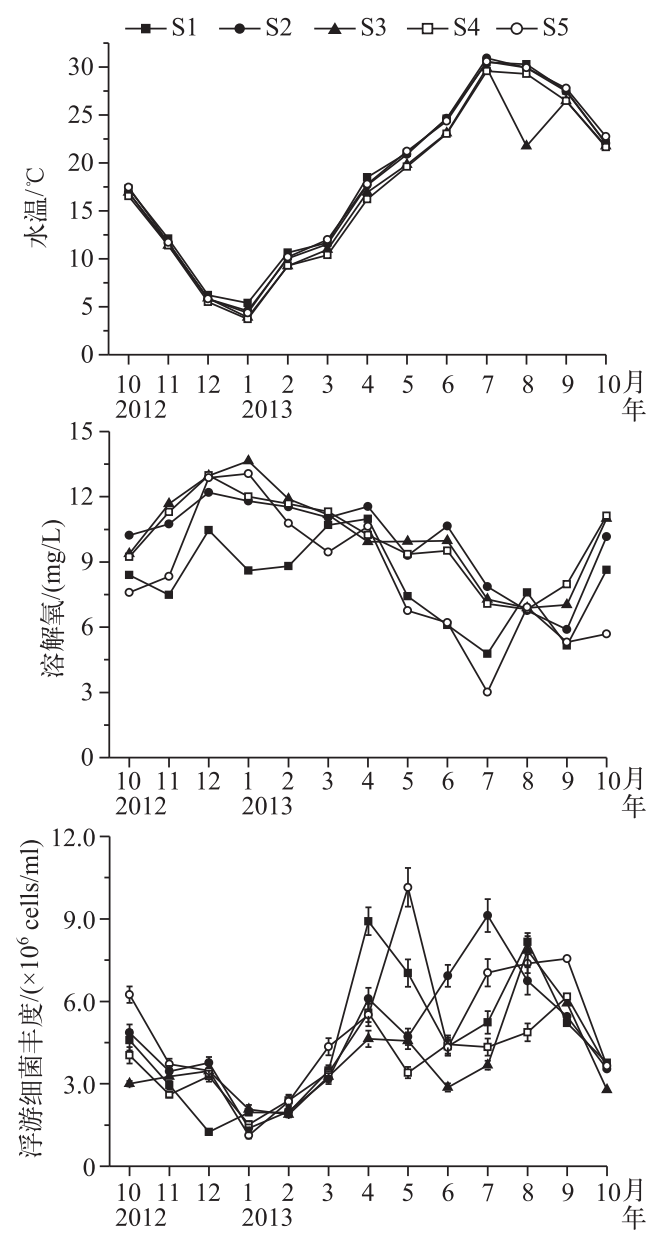

图 2 太湖西北湖区水温、溶解氧浓度和 浮游细菌丰度的时空变化

Fig.2 Temporal and spatial variation of water temperature, dissolved oxygen concentration and planktonic bacterial abundance in northwest region of Lake Taihu 
高. 5 个采样点 $\mathrm{PO}_{4}^{3-}-\mathrm{P}$ 浓度具有显著差异 $(P<0.001, n=65), \mathrm{S} 2$ 点位 $\mathrm{PO}_{4}^{3-}-\mathrm{P}$ 浓度最高, $\mathrm{S} 5$ 点位 $\mathrm{PO}_{4}^{3-}-\mathrm{P}$ 浓 度最低. $\mathrm{PO}_{4}^{3-}-\mathrm{P}$ 浓度季节波动较大, 所有采样点都在春季降至最低值, $\mathrm{S} 1$ 和 $\mathrm{S} 4$ 点位 $\mathrm{PO}_{4}^{3-}-\mathrm{P}$ 浓度在夏季逐 渐升高 (图 3).
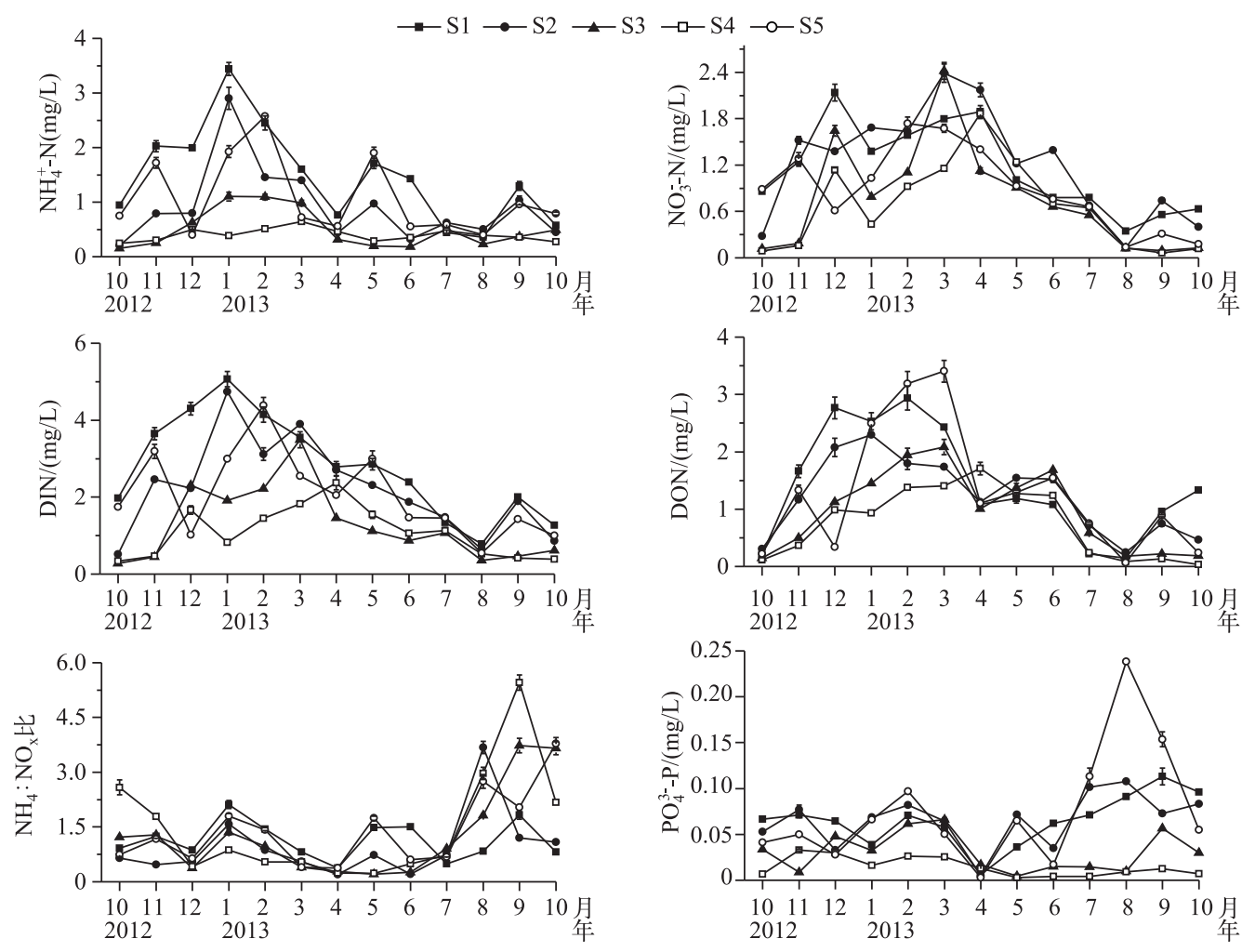

图 3 太湖西北湖区溶解性无机氮、溶解性有机氮和正磷酸盐浓度的时空变化

Fig.3 Temporal and spatial variation of dissolved inorganic nitrogen, dissolved organic nitrogen and phosphate concentrations in northwest region of Lake Taihu

\section{3 氮磷比的时空变化}

5 个采样点 TN :TP 比 $(P>0.05, n=65)$ 和 DIN :TP 比 $(P>0.05, n=65)$ 均没有显著差异. TN :TP 比变化 范围为 $4 \sim 61$, 其中 5 个采样点 $\mathrm{TN}: \mathrm{TP}$ 比在夏季基本上都小于 20 . DIN : TP 比变幅范围为 $1 \sim 31, \mathrm{~S} 3$ 和 S4 点位 在 2013 年 4-8 月期间, 迅速降低 (图 4).

\section{4 太湖西北湖区浮游植物生物量和细胞密度的时空变化以及优势属}

5 个采样点蓝藻、硅藻、绿藻和隐藻生物量所占比值平均值分别为 $34 \% \pm 15 \% 、 29 \% \pm 9 \% 、 25 \% \pm 13 \%$ 和 $9 \% \pm 0.1 \% .2013$ 年 4 月 S1 点位金藻生物量所占比值达到 7\%. 2012 年 12 月, S5 点位裸藻生物量所占比值达 到 48\%.S3 点位未发现裸藻, S1 点位未发现甲藻( 图 5). 浮游植物优势属包括微囊藻、鱼腥藻、颤藻、脆杆藻、 小环藻、直链硅藻、栅藻、小球藻、纤维藻、丝藻、四角藻、四星藻、十字藻和隐藻.

5 个采样点的蓝藻 $(P>0.05, n=65)$ 、绿藻 $(P>0.05, n=65)$ 和隐藻细胞密度 $(P>0.05, n=65)$ 均没有显 著差异, 但硅藻细胞密度存在显著差异 $(P<0.001, n=65) . S 1$ 点位蓝藻细胞密度从 2013 年 6 月的 $1.5 \times 10^{5}$ cells $/ \mathrm{L}$ 增加到 8 月的 $1.0 \times 10^{8}$ cells $/ \mathrm{L}, \mathrm{S} 2 、 \mathrm{~S} 4$ 和 S5 点位蓝藻细胞密度都在秋季 ( 2012 年 10 月和 2013 年 9 月) 达到最大值. S2 和 S5 硅藻细胞密度在 2013 年 2-4 月期间逐渐升高, 达到 3.4 $\times 10^{6} \mathrm{cells} / \mathrm{L}$. 绿藻与硅藻 细胞密度呈显著正相关 $(r=0.357, P<0.001, n=65)$, 除 S4 点位, 其他采样点都在秋季 ( 2013 年 $10-12$ 月) 达到最大值. 隐藻主要出现在春季 (2013 年 4-6 月) 和秋季, S2 点位隐藻细胞密度在 2013 年 6 月达到最大 


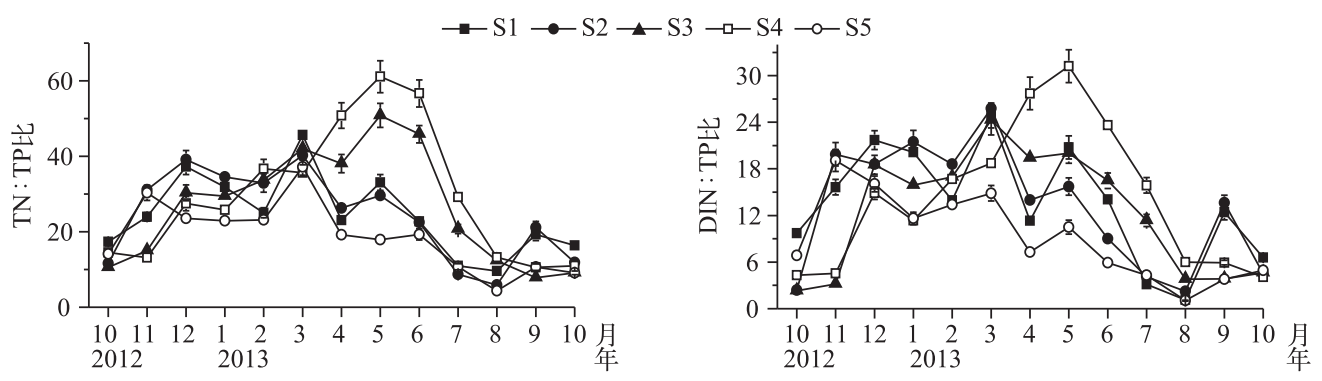

图 4 太湖西北湖区 $\mathrm{TN}: \mathrm{TP}$ 和 DIN :TP 比的时空变化

Fig.4 Temporal and spatial variation of ratio of TN :TP and DIN :TP in northwest region of Lake Taihu
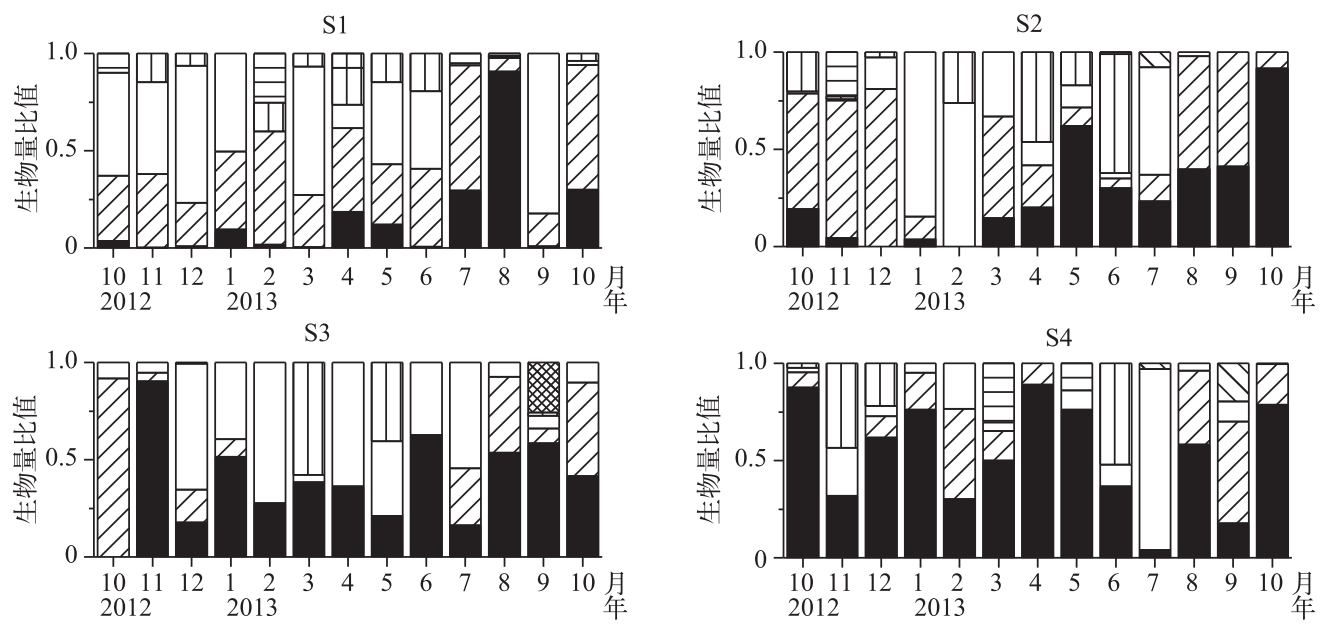

S5

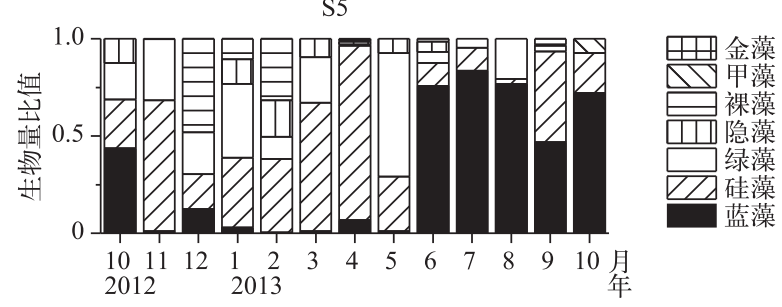

图 5 太湖西北湖区浮游植物群落组成的时空变化

Fig.5 Temporal and spatial variation of phytoplankton community in northwest region of Lake Taihu

值 $7.4 \times 10^{5}$ cells $/ \mathrm{L}$ (图 6).

\section{5 浮游植物与环境因子的相关分析}

物种数据经 DCA 分析得到第一轴梯度为 3.051, 因此采用单峰模型的排序方法 CCA. 物种与环境相关 性在 4 个轴上的累积变化率达到 $89.2 \%$,第一轴占 $44.3 \%$ (表 1). $\mathrm{NH}_{4}^{+}-\mathrm{N} 、 \mathrm{NO}_{3}^{-}-\mathrm{N}$ 和 DON 这 3 个环境因子与 第一物种排序轴呈正相关, 相关系数分别为 $0.5742 、 0.3610$ 和 $0.4462 . \mathrm{TN}: \mathrm{TP}$ 比与第二物种排序轴呈正相 关, 相关系数为 0.5961 . 蒙特卡洛检验值 $P=0.002<0.05$.

\section{3 讨论}

\section{1 太湖西北湖区浮游植物的时空分布特征}

本文研究发现, 太湖西北湖区浮游植物主要是由蓝藻、硅藻、绿藻和隐藻组成, 这与太湖以往的研究结 


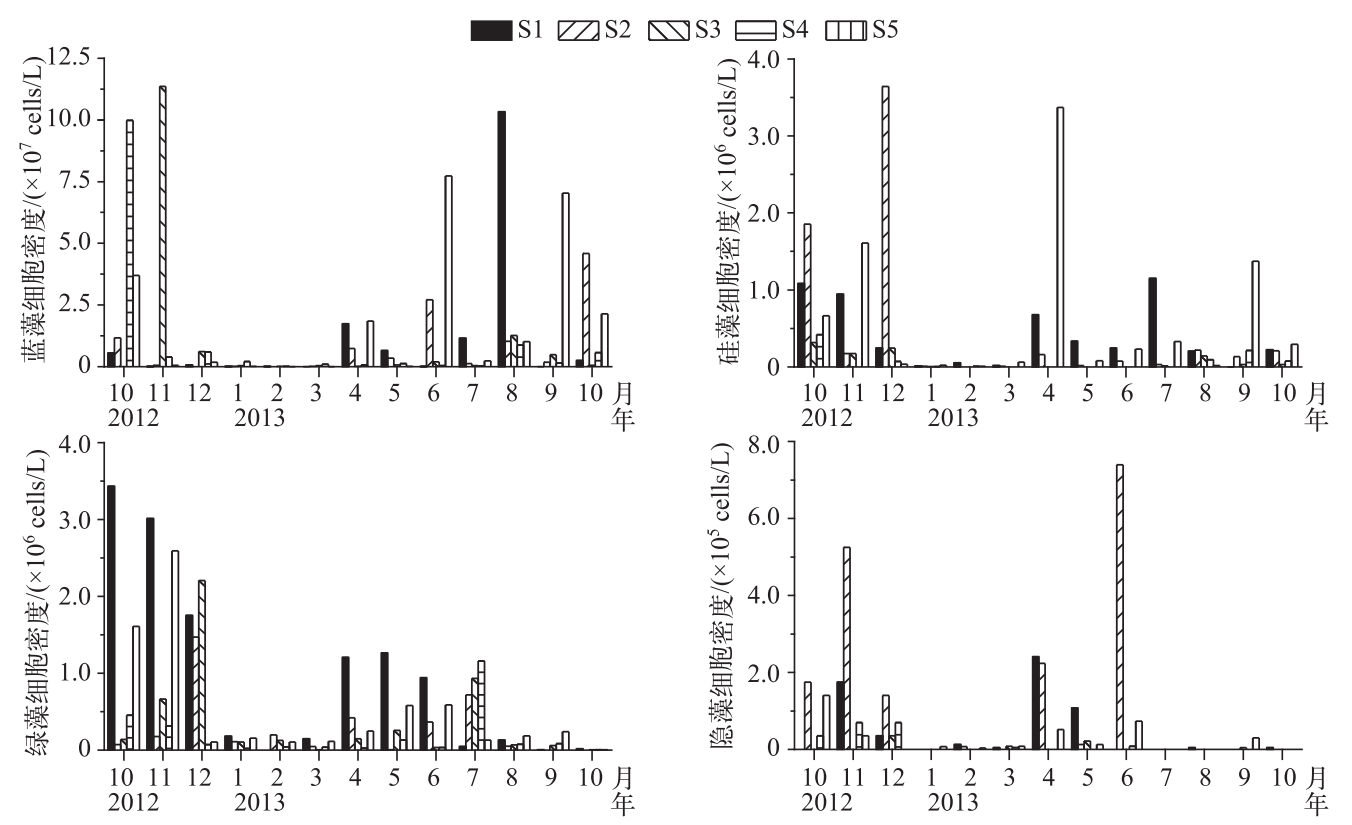

图 6 太湖西北湖区蓝藻、硅藻、绿藻和隐藻细胞密度的时空变化

Fig.6 Temporal and spatial variation of Cyanophyta, Bacillariophyta, Chlorophyta and Cryptophyta cell density in northwest region of Lake Taihu

果一致 ${ }^{[13]}$. 西北湖区蓝藻生物量在浮游植物中所占比例最高 (34\%), 但低于太湖另一重度富营养化湖 区一一梅梁湾 $(38 \%)^{[13]} .5$ 个采样点的蓝藻细胞密度没有显著差异, 可能是由于风、浪等混合作用的结 果 ${ }^{[14]}$. 有研究表明 ${ }^{[15]}$, 隐藻适宜低光照高有机质的水环境, 而太湖水体特点是悬浮物浓度高, 透明度低, 因 此隐藻和蓝藻的相互竞争演替趋势明显, 本文也发现 2013 年 3 和 6 月, S2、S3 和 S4 点位隐藻生物量所占比 例高于 50\%. 硅藻生物量所占比例 (25\%) 高于以往在太湖北部的研究结果 $(20 \%)^{[16]}$, 且河口区 S1 和 S5 点 位的硅藻细胞密度显著高于湖心区 $\mathrm{S} 4$. 邓建明等 ${ }^{[17]}$ 对太湖流域人湖河流浮游植物群落结构的研究结果表 明, 直链硅藻和脆杆藻是河流浮游植物中的优势属, 本文研究也表明直链硅藻和脆杆藻是西北湖区优势属. 因此, 陈东港和殷村港 2 条人湖河流中的硅藻可能受水流驱动而漂人河口. 此外, 硅藻细胞密度与绿藻细胞 密度呈显著正相关 $(r=0.357, P<0.001, n=65)$, 直链硅藻、小环藻和栅藻、四角藻都分布在第四象限 (图 7 ), 说明硅藻和绿藻 2 种藻类所需的生态环境条件基本一致,这与李娣等 ${ }^{[18]}$ 在太湖的研究结果相一致.

\section{2 太湖西北湖区无机氮的时空变化}

$\mathrm{NH}_{4}^{+}-\mathrm{N}$ 是夏季西北湖区水体 DIN 的主要组分. 大量研究表明, 藻类吸收利用、沉积物释放以及河道输人 和蓝藻本身死亡分解都是影响其动态变化的重要因素 ${ }^{[19-20]}$. 本文研究发现, 蓝藻细胞密度与 $\mathrm{NH}_{4}^{+}-\mathrm{N}$ 浓度呈 显著负相关, 而与 $\mathrm{PO}_{4}^{3-}-\mathrm{P}$ 没有显著相关性 (表 2), 表明夏季蓝藻大量生长吸收利用营养盐可能是引起 $\mathrm{NH}_{4}^{+}-\mathrm{N}$ 浓度迅速降低的重要原因. 此外, 西北湖区水体 DO 在 2013 年 7-9 月期间降至最低值,其中 S5 点位 DON 浓度仅为 $3.0 \mathrm{mg} / \mathrm{L}$. 由于西湖区是太湖湖泛易发区域,并且有研究表明,太湖 DO 在夏季会出现短时间 尺度上的分层现象 ${ }^{[21]}$, 因此并不排除水体会出现间歇性厌氧. 范成新等 ${ }^{[20]}$ 在太湖研究发现, 夏季气温较高, 有利于沉积物分解, 形成水体缺氧或厌氧环境, 从而增加沉积物 $\mathrm{NH}_{4}^{+}-\mathrm{N}$ 的释放. 因此, 夏季沉积物 $\mathrm{NH}_{4}^{+}-\mathrm{N}$ 的 释放可能是西北湖区水体中 $\mathrm{NH}_{4}^{+}-\mathrm{N}$ 的重要来源. 本文研究发现, 夏季水体 $\mathrm{NH}_{4}^{+}-\mathrm{N}$ 浓度最低降至 $0.23 \mathrm{mg} / \mathrm{L}$, 因此推测, 春夏季蓝藻在生长过程中消耗的 $\mathrm{NH}_{4}^{+} \mathrm{-}$ 通过沉积物释放得以补充, 这也解释了为什么蓝藻细胞 密度与 $\mathrm{NH}_{4}^{+}-\mathrm{N}$ 的相关系数较低. 


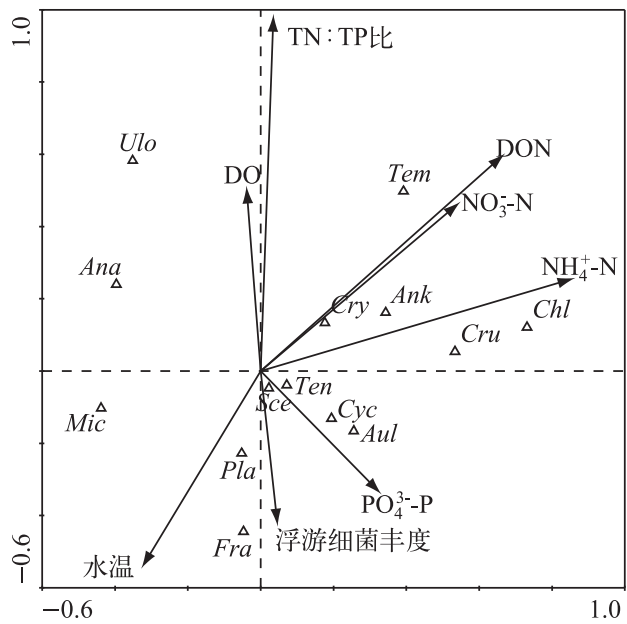

图 7 环境因素与浮游植物 CCA 排序图

(微囊藻 $M i c$, 鱼腥藻 $A n a$, 颤藻 $P l a$, 脆杆藻 $F r a$, 小环藻 $C y c$, 直链硅藻 $A u l$, 栅藻 $S c e$, 小球藻 $C h l$, 纤维藻 $A n k$, 丝藻 $U l o$, 四角藻 $T e n$, 四星藻 $T e m$, 十字藻 $C r u$, 隐藻 $C r y)$

Fig.7 CCA ordination diagram of the environmental factors and phytoplankton community

表 1 浮游植物组成与环境因子 CCA 分析结果

Tab.1 Results from CCA of dominant genera in relation to environmental factors

\begin{tabular}{|c|c|c|c|c|}
\hline & 排序轴 1 & 排序轴 2 & 排序轴 3 & 排序轴 4 \\
\hline 特征值 ～～～～～～ & 0.107 & 0.063 & 0.029 & 0.017 \\
\hline 种类与环境因子相关系数 & 0.695 & 0.628 & 0.474 & 0.416 \\
\hline 累积百分比变化率 物种 & 9.5 & 15.0 & 17.6 & 19.1 \\
\hline 物种-环境相关性 & $44.3 \%$ & $70.2 \%$ & $82.3 \%$ & $89.2 \%$ \\
\hline
\end{tabular}

表 2 蓝藻细胞密度与环境因子的 Pearson 相关分析

Tab.2 Pearson correlation coefficient of Cyanophyta abundance and environmental factors

\begin{tabular}{|c|c|c|c|c|c|c|c|c|c|c|}
\hline & 水温 & DO & $\mathrm{NH}_{4}^{+}-\mathrm{N}$ & $\mathrm{NO}_{3}^{-}-\mathrm{N}$ & DON & $\mathrm{TN}$ : TP 比 & $\mathrm{NH}_{4}: \mathrm{NO}_{\mathrm{x}}$ 比 & DIN :TP 比 & $\begin{array}{l}\text { 浮游细 } \\
\text { 菌丰度 }\end{array}$ & $\mathrm{PO}_{4}^{3-}-\mathrm{P}$ \\
\hline 蓝藻细胞密度 & 0.198 & -0.141 & $-0.254^{*}$ & $-0.321 * *$ & $-0.300^{*}$ & $-0.352^{* *}$ & 0.066 & $-0.459^{* *}$ & 0.225 & 0.005 \\
\hline
\end{tabular}

* 表示显著相关 $P<0.05, * *$ 表示极显著相关 $P<0.01$.

McCarthy 等 ${ }^{[22]}$ 在全太湖研究发现, $\mathrm{NH}_{4}: \mathrm{NO}_{\mathrm{x}}$ 比的季节变化规律为冬春季逐渐降低,夏季基本稳定,秋 季逐渐升高. 这与本文的研究结果并不完全一致, 西北湖区 $\mathrm{NH}_{4}: \mathrm{NO}_{\mathrm{x}}$ 比在夏季逐渐增加, 表明太湖各湖区 $\mathrm{NH}_{4}: \mathrm{NO}_{\mathrm{x}}$ 比可能存在显著差异. 此外, DIN 的组分对浮游植物群落结构具有重要影响, 在美国 Okeechobee 湖 研究发现 ${ }^{[22]}$, 随着 $\mathrm{NH}_{4}: \mathrm{NO}_{\mathrm{x}}$ 比升高, 蓝藻在浮游植物生物量中所占比值增加, 硅藻所占比值降低. 本文也发 现, 西北湖区 5 个采样点 $\mathrm{NH}_{4}: \mathrm{NO}_{\mathrm{x}}$ 比在冬季逐渐降低, 硅藻在浮游植物生物量中所占比值由 $23 \% \pm 14 \%$ 增加 到 32\% $\pm 26 \%$, 由于硅藻对 $\mathrm{NO}_{3}^{-}-\mathrm{N}$ 的吸收利用 ${ }^{[3]}$, 因此夏季 $\mathrm{S} 1 、 \mathrm{~S} 3$ 和 $\mathrm{S} 4$ 点位 $\mathrm{NH}_{4}: \mathrm{NO}_{\mathrm{x}}$ 比升高, 并且 $\mathrm{S} 3$ 点位 蓝藻在浮游植物生物量中所占比值由 $16 \%$ 增加到 $59 \%$. 这与周涛 ${ }^{[23]}$ 在太湖野外监测中的结果相一致, 氮源 中 $\mathrm{NH}_{4}^{+}-\mathrm{N}$ 比例的升高有利于增强蓝藻的竞争优势.

本文研究发现, 春季和早夏西北湖区水体 DIN 的主要组分是 $\mathrm{NO}_{3}^{-}-\mathrm{N}$, 这与富营养化湖泊巢湖的研究结 果一致 ${ }^{[24]}$. 春季太湖流域农田生态系统开始大量使用氮肥, 吴庆乐等 ${ }^{[25]}$ 通过同位素示踪研究发现氮肥是太 
湖水体 $\mathrm{NO}_{3}^{-}-\mathrm{N}$ 的重要来源. 此外春季属于丰水期 ${ }^{[26]}$, 太湖流域水稻田中氮素流失的主要形态是 $\mathrm{NO}_{3}^{-}-\mathrm{N}^{[27]}$, 因此 $\mathrm{NO}_{3}^{-}-\mathrm{N}$ 浓度在春季达到峰值. 冯露露等 ${ }^{[28]}$ 通过对太湖 1 年的野外监测数据进行相关分析研究发现, 微 囊藻丰度与 $\mathrm{NO}_{3}^{-}-\mathrm{N}$ 浓度呈显著负相关, 而本文也研究发现, 蓝藻细胞密度与 $\mathrm{NO}_{3}^{-}-\mathrm{N}$ 浓度呈显著负相关 (表 2 ), 这些研究结果表明, $\mathrm{NO}_{3}^{-}-\mathrm{N}$ 可以被蓝藻吸收利用.

\section{3 太湖西北湖区水体氮限制}

近来大量研究结果表明,在富营养化湖泊蓝藻水华暴发期间, 水体容易出现氮限制 ${ }^{[4,29]} \cdot \mathrm{Xu}$ 等 ${ }^{[4]}$ 在太 湖北部研究发现, 夏季水体出现氮限制时 $\mathrm{NH}_{4}^{+}-\mathrm{N}$ 浓度降至 $0.05 \mathrm{mg} / \mathrm{L}, \mathrm{NO}_{3}^{-}-\mathrm{N}$ 浓度降至 $0.65 \mathrm{mg} / \mathrm{L}$. 本研究也 发现夏季蓝藻细胞密度最高达到 $1.0 \times 10^{8}$ cells $/ \mathrm{L}$ 时, 除 $\mathrm{S} 1$ 点位, 其他点位在 2013 年 8 月 $\mathrm{NO}_{3}^{-}-\mathrm{N}$ 浓度均低于 $0.15 \mathrm{mg} / \mathrm{L}$. 一般认为浮游植物利用 $\mathrm{NH}_{4}^{+}-\mathrm{N}$ 消耗的能量少, $\mathrm{NH}_{4}^{+}-\mathrm{N}$ 是浮游植物优先利用的氮素形式, 只有 $\mathrm{NH}_{4}^{+}-\mathrm{N}$ 耗尽后才吸收 $\mathrm{NO}_{3}^{-}-\mathrm{N}$. 因此, 夏季较低的 $\mathrm{NO}_{3}^{-}-\mathrm{N}$ 浓度表明水体可能出现氮限制, 而通过上文分析, 沉 积物中 $\mathrm{NH}_{4}^{+}-\mathrm{N}$ 的释放可能是维持水体保持较高 $\mathrm{NH}_{4}^{+}-\mathrm{N}$ 浓度的重要因素.

此外, TN : TP 比也被广泛应用以表征湖泊中浮游植物生长过程出现的氮磷限制作用, 但湖泊的富营养 化级别对该阈值具有重要影响 ${ }^{[30]}$. 有研究表明, 重度富营养化湖泊 TN : TP 比低于 9.5 表明水体出现氮限 制 ${ }^{[30]}$. 此外, DIN :TP 比低于4也可以指示水体出现氮限制 ${ }^{[31]}$. 本研究发现由于春季春耕农田大量施加氮肥, 水体氮磷比升高; 夏季高温和间歇性缺氧反硝化作用引起氮素损失导致氮磷比降低. 2013 年 7 月,太湖西北 湖区 S2 点位 TN : TP 比为 $8.7, \mathrm{~S} 1$ 点位 DIN : TP 比为 $3.1 ; 2013$ 年 8 月, S5 和 S2 点位 TN : TP 比分别为 4.4 和 $5.9 ; 2013$ 年 9 月, $\mathrm{S} 3$ 点位 $\mathrm{TN}: \mathrm{TP}$ 比为 $7.9, \mathrm{~S} 3$ 和 $\mathrm{S} 5$ 点位 DIN : TP 比为 3.8 . 因此,氮磷比以及水体的实际氮磷 浓度表明,太湖西北湖区夏季水体可能出现氮限制, 这与以往在太湖藻型湖区一梅梁湾的研究结果相 一致 $[4]$.

\section{4 太湖西北湖区有机氮的时空变化}

西北湖区 DON 浓度与 $\mathrm{NO}_{3}^{-}-\mathrm{N}$ 和 $\mathrm{NH}_{4}^{+}-\mathrm{N}$ 浓度均呈显著正相关, 表明部分 DON 与 DIN 具有相同的来源 机制. 有研究表明, 浮游植物 ${ }^{[6]}$ 和沉积物 ${ }^{[32]}$ 释放的 DON 是水体中 DON 的重要来源, 在洱海沉积物中发现 DON 在 TDN 中所占比例达到 $40 \%{ }^{[33]}$. 在 Kinneret 湖 ${ }^{[6]}$ 、英格兰河口 ${ }^{[34]}$ 研究发现浮游植物以及浮游细菌释 放 DON 引起 DON 在 TDN 中的所占比例呈春季低、秋季高的季节变化规律, 但本文研究结果与此相反, 综上 所述,沉积物中 DON 的释放可能是太湖西北湖区 DON 的主要来源.

有研究表明,DON 中尿素、游离态氨基酸具有一定生物可利用性, 尿素浓度的升高可以促进微囊藻的生 长 $^{[35-36]}$. 韩晓霞等 ${ }^{[37]}$ 在太湖研究发现, 西北湖区尿素浓度最高可达 $0.078 \mathrm{mg} / \mathrm{L}$; 杨柳等 ${ }^{[38]}$ 在梅梁湾研究发 现浮游植物对尿素的吸收速率低于 $\mathrm{NH}_{4}^{+}-\mathrm{N}$ 但高于 $\mathrm{NO}_{3}^{-}-\mathrm{N}$. 本文研究发现西北湖区 DON 与蓝藻细胞密度呈 显著负相关 (表 2). 因此, 太湖西北湖区夏季水体出现氮限制时, DON 可能是蓝藻氮素利用的重要补充. 这 与在日本海的研究结果相一致 ${ }^{[39]}$, 蓝藻水华期间水体出现氮限制, 表征蓝藻生物量的特征色素一玉米黄素 与 DON 浓度呈显著负相关. 此外, 有研究表明 DON 能被生物和光降解生成 $\mathrm{NH}_{4}^{+}-\mathrm{N}^{[40-42]}$, 因此蓝藻对 DON 的利用也可能是通过间接吸收利用 DON 生物和光降解再生的 DIN 这一途径. 但也有研究表明, 浮游细菌可 以吸收利用 DON 中的游离态氨基酸 ${ }^{[43]}$, 本文研究发现, 2013 年 6-8 月期间, S1 和 S5 点位 DON 浓度迅速 降低, 浮游细菌丰度逐渐升高. 因此, 浮游细菌对 DON 的分解利用可能也是影响 DON 变化的重要因素.

\section{4 结论}

1) 太湖西北湖区表层水体浮游植物主要是由蓝藻、硅藻、绿藻和隐藻组成. 5 个采样点的蓝藻细胞密度 没有显著差异, 可能是受到风、浪等混合作用的结果. 硅藻与绿藻细胞密度呈显著正相关, 直链硅藻、小环藻 和棶藻、四角藻分布在同一象限, 表明调查中出现的硅藻和绿藻所需的生态环境条件基本一致. 春季和早 夏, 部分点位隐藻相对生物量高于 $50 \%$, 表明隐藻与蓝藻的相互竞争趋势显著.

2) CCA 排序图结果表明, 无机 $\left(\mathrm{NH}_{4}^{+}-\mathrm{N} 、 \mathrm{NO}_{3}^{-}-\mathrm{N}\right)$ 和有机氮 ( DON) 浓度以及 $\mathrm{TN}$ : TP 比是影响太湖西北湖 区浮游植物优势属分布的重要环境因子. 春季施肥是太湖 $\mathrm{NO}_{3}^{-}-\mathrm{N}$ 的主要来源, 蓝藻细胞密度与 $\mathrm{NO}_{3}^{-}-\mathrm{N}$ 浓度 呈显著负相关, 表明蓝藻对 $\mathrm{NO}_{3}^{-}-\mathrm{N}$ 的吸收利用是影响其变化的重要因素. 沉积物 $\mathrm{NH}_{4}^{+}-\mathrm{N}$ 的释放使得蓝藻细 
胞密度与 $\mathrm{NH}_{4}^{+}-\mathrm{N}$ 的显著相关性水平和相关系数与 $\mathrm{NO}_{3}^{-}$相比较低.

3) 西北湖区 TN :TP 比和 DIN :TP 比从春季开始逐渐降低, 在夏季降至最低值, 湖区平均值分别为 $9 \pm 4$ 和 $3 \pm 2$. 并且夏季 $\mathrm{NO}_{3}^{-}-\mathrm{N}$ 浓度降至 $0.15 \mathrm{mg} / \mathrm{L}$, 表明浮游植物, 尤其是蓝藻的生长可能受到氮素限制作用.

4 ) 沉积物中 DON 的释放可能是 DON 的重要来源, 其在 TDN 中所占比例呈夏季低、春季高的季节变化 规律, 并且与蓝藻细胞密度呈显著负相关, 表明在氮限制条件下, 可能是蓝藻氮素利用的重要补充.

\section{5 参考文献}

[ 1 ] Ferber LR, Levine SN, Lini A et al. Do cyanobacteria dominated in eutrophic lakes because they fix atmospheric nitrogen? Freshwater Biology, 2004, 49(6): 690-708.

[ 2 ] Lu Na, Yin Hongbin, Deng Jiancai et al. Spring community structure of phytoplankton from Lake Chaohu and its relationship to environmental factors. J Lake Sci, 2010, 22(6) : 950-956. DOI: 10.18307/2010.0620. [ 路娜, 尹洪斌, 邓建才 等. 巢湖流域春季浮游植物群落结构特征及其与环境因子的关系. 湖泊科学, 2010, 22(6) : 950-956.]

[ 3 ] Heil CA, Revilla M, Glibert PM et al. Nutrient quality drives differential phytoplankton community composition on the southwest Florida Shelf. Limnology and Oceanography, 2007, 52(3) : 1067-1078.

[ 4 ] Xu H, Paerl HW, Qin BQ et al. Nitrogen and phosphorus inputs control phytoplankton growth in eutrophic Lake Taihu, China. Limnology and Oceanography, 2010, 55(1): 420-432.

[ 5 ] Kagami M, Hirose Y, Ogura H. Phosphorus and nitrogen limitation of phytoplankton growth in eutrophic Lake Inba, Japan. Limnology, 2013, 14(1): 51-58.

[6] Berman T, Bronk DA. Dissolved organic nitrogen: A dynamic participant in aquatic ecosystems. Aquatic Microbial Ecology, 2003, 31: 279-305.

[ 7 ] Bronk DA, See JH, Bradley P et al. DON as a source of bioavailable nitrogen for phytoplankton. Biogeosciences, 2007, 4 (3) : 283-296.

[ 8 ] Dai R, Liu H, Qu J et al. Effects of amino acids on microcystin production of the Microcystis aeruginosa. Journal of Hazardous Material, 2009, 161(2/3) : 730-736.

[ 9 ] Liu Jutao, Yang Yongsheng, Gao Junfeng et al. Characteristics of cyanobacteria bloom grading and its temporal and spatial variation in Taihu Lake. Resources and Environment in the Yangtze Basin, 2011, 20(2): 156-160. [刘聚涛, 杨永生, 高 俊峰等. 太湖蓝藻水华分级及其时空变化. 长江流域资源与环境, 2011, 20(2)：156-160.]

[10] Hu Hongjun, Wei Yinxin eds. The freshwater algae of China-Systematic, taxonomy and ecology. Beijing: Science Press, 2006: 100-150. [胡鸿钧, 魏印心. 中国淡水藻类: 系统、分类及生态. 北京: 科学出版社, 2006: 100-150.]

[11] Chen Weimin, Huang Xiangfei, Zhou Wanping eds. Observation methods in lake ecocystem. Beijing: China Environmental Sciences Press, 2005: 122-130. [陈伟民, 黄祥飞, 周万平. 湖泊生态系统观测方法. 北京: 中国环境科学出版社, 2005: 122-130.]

[12] Sun Cuici, Wang Youshao, Sun Song et al. Analysis dynamics of phytoplankton community characteristics in Daya Bay. Acta Ecologica Sinica, 2006, 26(12) : 3948-3958. [孙翠慈, 王友绍, 孙松等. 大亚湾浮游植物群落特征. 生态学报, 2006, 26(12) : 3948-3958.]

[13] Chen YW, Qin BQ, Teubner K et al. Long-term dynamics of phytoplankton assemblages: Microcystis-domination in Lake Taihu, a large shallow lake in China. Journal of Plankton Research, 2003, 25(1) : 445-453.

[14] Wu Tingfeng, Zhu Gangwei, Qin Boqiang et al. Prior wind field induced hydrodynamics and its influence on cyanobacterial bloom in northern bays of Lake Taihu, China. J Lake Sci, 2012, 24(3) : 409-415. DOI: 10.18307/2012.0312. [吴挺 峰, 朱广伟, 秦伯强等. 前期风场控制的太湖北部湖湾水动力及其对蓝藻水华影响. 湖泊科学, 2012, 24(3): 409-415.]

[15] Liu Xia, Lu Xiaohua, Chen Yuwei. Temporal and spatial dynamics of Cryptophytes biomass in the north of Lake Taihu. $J$ Lake Sci, 2012, 24(1) : 142-148. DOI: 10.18307/2012.0120. [刘霞, 陆晓华, 陈宇炜. 太湖北部隐藻生物量时空动 态. 湖泊科学, 2012, 24(1) : 142-148.]

[16] Liu Xia, Lu Xiaohua, Chen Yuwei. Long-term evolution of planktonic diatoms and their relationships with environmental factors in Lake Taihu. Acta Scientiae Circumstantiae, 2012, 32(4): 821-827. [刘霞, 陆晓华, 陈宇炜. 太湖浮游硅藻 时空演化与环境因子的关系. 环境科学学报, 2012, 32(4): 821-827.] 
[17] Deng Jianming, Xu Caiping, Chen Yuwei et al. Comparison of the phytoplankton community in major rivers of the Taihu Basin. Resources Science, 2011, 32(2) : 210-216. [ 邓建明, 徐彩平, 陈宇炜等. 太湖流域主要河道浮游植物类群对 比研究. 资源科学, 2011, 32(2): 210-216.]

[18] Li Di, Li Xuwen, Niu Zhichun et al. Structure of phytoplankton community and relationship between phytoplankton community and water quality in Taihu Lake. Ecology and Environmental Sciences, 2014, 23(11): 1814-1820. [李娣, 李旭 文, 牛志春等. 太湖浮游植物群落结构及其与水质指标间的关系. 生态环境学报, 2014, 23(11): 1814-1820.]

[19] Wu Yali, Xu Hai, Yang Guijun et al. Progress in nitrogen pollution research in Lake Taihu. J Lake Sci, 2014, 26(1): 19-28. DOI : 10.18307/2014.0103. [ 吴雅丽, 许海, 杨桂军等. 太湖水体氮素污染状况研究进展. 湖泊科学, 2014, 26(1): 19-28.]

[20] Fan Chengxin, Zhang Lu, Qin Boqiang et al. Migration mechanism of biogenic elements and their quantification on sediment-water interface of Lake Taihu: I. Spatial variation of the ammonium release rates and its source and sink fluxes. $J$ Lake Sci, 2004, 16(1) : 10-20. DOI: 10.18307/2004.0102. [范成新, 张路, 秦伯强等. 太湖沉积物-水界面生源要 素迁移机制及定量化一1. 铵态氮释放速率的空间差异及源-汇通量. 湖泊科学, 2004, 16(1): 10-20.]

[21] Zhao Linlin, Zhu Mengyuan, Feng Longqing et al. Stratification and its driving factors of water physicochemical variables in large shallow Lake Taihu. J Lake Sci, 2011, 23(4) : 649-656. DOI : 10.18307/2011.0423. [赵林林, 朱梦圆, 冯龙 庆等. 太湖水体理化指标在夏季短时间尺度上的分层及其控制因素. 湖泊科学, 2011, 23(4): 649-656]

[22] McCarthy MJ, James RT, Chen Y et al. Nutrient ratios and phytoplankton community structure in the large, shallow, eutrophic, subtropical Lakes Okeechobee (Florida, USA) and Taihu (China). Limnology, 2009, 10(3) : 215-227.

[23] Zhou Tao. The role of nitrogen in bloom formation and maintenance of Lake Taihu [Dissertation]. Nanjing: Nanjing University, 2013. [ 周涛. 氮在太湖水华形成与维持中的作用 [学位论文].南京: 南京大学, 2013.]

[24] Zhang M, Xu J, Xie P. Nitrogen dynamics in large shallow eutrophic Lake Chaohu, China. Environmental Geology, 2008, $\mathbf{5 5}(1): 1-8$.

[25] Wu Qingle, Ruan Xiaohong, Wu Chaoming et al. Analyses of sources and transformation of nitrogen as a contaminant in the river and lake water in the western region of Taihu Lake basin. Acta Scientiae Circumstantiae, 2015, 35( 12) : 38833889. [ 吴庆乐, 阮晓红, 吴朝明等. 太湖西部河湖氮污染物来源及转化途径分析. 环境科学学报, 2015, 35(12): 3883-3889. ]

[26] Qin B, Xu P, Wu Q et al. Environmental issues of Lake Taihu, China. Hydrobiologia, 2007, 581 : 3-14.

[27] Zhang Gang. Study on N \& P pollution flux from agricultural non-point sources of the main paddy soils in Tai-Lake region [Dissertation]. Nanjing: Nanjing Agricultural University, 2007. [张刚. 太湖地区主要类型稻田氮磷面源污染通量的 研究 [ 学位论文]. 南京: 南京农业大学, 2007.]

[28] Feng Lulu, Li Zhengkui, Zhou Tao. Temporal and spatial distribution of phytoplankton and various forms of inorganic nitrogen in Lake Taihu. J Lake Sci, 2012, 24(5) : 739-745. DOI: 10.18307/2012.0515. [冯露露, 李正鬼, 周涛. 太湖浮 游植物和各种形态无机氮的时空分布特征. 湖泊科学, 2012, 24(5): 739-745.]

[29] Chaffin JD, Bridgeman TB, Bade DL. Nitrogen constrains the growth of lake summer cyanobaceria blooms in Lake Erie. Advances in Microbiology, 2013, 3: 16-26.

[30] Abell JM, Özkundakci D, Hamilton DP. Nitrogen and phosphorus limitation of phytoplankton growth in New Zealand lakes: Implications for eutrophication control. Ecosystems, 2010, 13(7) : 966-977.

[31] Matthews R, Hilles M, Pelletier G. Determining trophic state in Lake Whatcom, Washington ( USA), a soft water lake exhibiting seasonal nitrogen limitation. Hydrobiologia, 2002, 468(1/2/3) : 107-121.

[32] Zehr JP, Paulsen SG, Axler RP et al. Dynamics of dissolved organic nitrogen in subalpine Castle Lake, California. Hydrobiologia, 1988, 157(1) : 33-45.

[33] Gao Yuewen, Wang Shengrui, Zhang Weihua et al. Seasonal variations of dissolved organic nitrogen in sediments of Lake Taihu. Research of Environmental Sciences, 2012, 25(6): 659-665. [高悦文, 王圣瑞, 张伟华等. 洱海沉积物中溶解 性有机氮季节性变化. 环境科学研究, 2012, 25(6): 659-665.]

[34] Badr EA, Tappin AD, Achterberg EP. Distributions and seasonal variability of dissolved organic nitrogen in two estuaries in SW England. Marine Chemistry, 2008, 110: 153-164.

[35] Davis TW, Harke MJ, Marcoval MA et al. Effects of nitrogenous compounds and phosphorus on the growth of toxic and non-toxic strains of Microcystis during bloom events. Aquatic Microbial Ecology, 2010, 61: 149-162. 
[36] Donald DB, Bogard MJ, Finlay K et al. Comparative effects of urea, ammonium, and nitrate on phytoplankton abundance, community composition, and toxicity in hypereutrophic freshwaters. Limnology and Oceanography, 2011, 56 ( 6) : 2161-2175.

[37] Han Xiaoxia, Zhu Guangwei, Xu Hai et al. Source analysis of urea-N in Lake Taihu during summer. Environmental Science, 2014, 35(7) : 2547-2556. [ 韩晓霞, 朱广伟, 许海等. 太湖夏季水体中尿素的来源探析. 环境科学, 2014,35 ( 7$):$ 2547-2556.]

[38] Yang Liu, Zhang Ming, Liu Zhengwen. Uptake of various forms of nitrogen by phytoplankton community in spring in Lake Taihu. J Lake Sci, 2011, 23(4) : 605-611. DOI: 10.18307/2011.0417. [杨柳, 章铭, 刘正文. 太湖春季浮游植物群 落对不同形态氮的吸收. 湖泊科学, 2011, 23(4) : 605-611.]

[39] Kim TH, Kim G. Factors controlling the C : N : P stoichiometry of dissolved organic matter in the N-limited, cyanobacteria-dominated East/Japan Sea. Journal of Marine Systems, 2013, 115/116: 1-9.

[40] Tupas L, Koike I. Simultaneous uptake and regeneration of ammonium by mixed assemblages of heterotrophic marine bacteria. Marine Ecology Progress Series, 1991, 70: 273-282.

[41] Grzybowski W. The significance of dissolved organic matter photodegradation as a source of ammonium in natural waters. Oceanologia, 2002, 44(3) : 355-365.

[42] Vähätalo AV, Zepp RG. Photochemical mineralization of dissolved organic nitrogen to ammonium in the Baltic Sea. Environmental Science\& Technology, 2005, 39(18) : 6985-6992.

[43] Bradley PB, Sanderson MP, Frischer ME et al. Inorganic and organic nitrogen uptake by phytoplankton and heterotrophic bacteria in the stratified Mid-Atlantic Bight. Estuarine, Coastal and Shelf Science, 2010, 88: 429-441. 